BMJ Open

Sport \&

Exercise

Medicine

\title{
Research priorities of international sporting federations and the IOC research centres
}

\author{
Caroline F Finch, ${ }^{1}$ Scott Talpey, ${ }^{1}$ Ashley Bradshaw, ${ }^{1}$ Torbjorn Soligard, ${ }^{2}$ \\ Lars Engebretsen $2,3,4$
}

\section{ABSTRACT}

To cite: Finch CF, Talpey $S$, Bradshaw A, et al. Research priorities of international sporting federations and the IOC research centres. BMJ Open Sport Exerc Med 2016;2:e000168. doi:10.1136/bmjsem-2016000168

- Prepublication history for this paper is available online To view these files please visit the journal online (http://dx.doi.org/10.1136/ bmjsem-2016-000168).

Accepted 28 September 2016

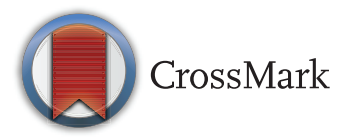

${ }^{1}$ Australian Collaboration for Research into Injury in Sport and its Prevention (ACRISP), Federation University Australia, Ballarat, Victoria, Australia

${ }^{2}$ Medical and Scientific Department, International Olympic Committee, Lausanne, Switzerland ${ }^{3}$ Oslo Sports Trauma Research Center (OSTRC), Norwegian School of Sports Sciences, Oslo, Norway ${ }^{4}$ Department of Orthopaedic Surgery, Oslo University Hospital, Oslo, Norway

Correspondence to Professor Caroline Finch; c.finch@federation.edu.au (IOC-RCs).
Background/aim: To be fully effective, the prevention of injury in sport and promotion of athlete's health needs to be both targeted and underpinned by scientific evidence. This study aimed to identify the research priorities of International Sporting Federation (ISFs) compared to the current research focus of the International Olympic Committee Research Centres

Methods: Online survey of ISF Medical Chairpersons $(\mathrm{n}=22,69 \%$ response) and IOC-RC Directors ( $n=7,78 \%$ response). Open-ended responses relating to injury/illness priorities and specific athlete targets were thematically coded. Ratings were given of the need for different research types according to the Translating Research into Injury Prevention Practice (TRIPP) Framework stages. Results are presented as the frequency of ISFs and IOC-RCs separately.

Results: Both ISFs and IOC-RFs prioritised research into concussion $(27 \%, 72 \%$, respectively), competitive overuse $(23 \%, 43 \%)$ and youth $(41 \%, 43 \%)$. The ISFs also ranked catastrophic injuries $(14 \%)$, environmental factors $(18 \%)$, elite athletes (18\%) and Paralympic athletes (14\%) as important. The IOC-RCs gave higher priority to preventing respiratory illness (43\%), longterm health consequences of injury $(43 \%)$ and recreational athletes $(43 \%)$. There was a trend towards ISFs valuing TRIPP stage $5 / 6$ research more highly and for the IOC-RCs to value TRIPP stage 1/2 research.

Conclusions: There are clear opportunities to better link the priorities and actions of the ISFs and IOC-RCs, to ensure more effective practice-policy-research partnerships for the benefit of all athletes. Setting a mutually-agreed research agenda will require further active engagement between researchers and broader ISF representatives.

\section{INTRODUCTION}

To be fully effective, the prevention of injury and promotion of health in athletes needs to be both targeted and underpinned by scientific evidence. Prioritisation of effort can be based on different criteria, including addressing issues that are the most: important, common, severe, preventable or resourced. It

\section{What are the new findings?}

- Research Centres and International Sporting Federations have a strong interest, and engagement, in research to prevent injury and illness in athletes.

- Their research priorities align well for concussion, anterior cruciate ligament injuries and chronic overuse injuries, with particular emphasis on youth.

- Research centres, but not International Sporting Federations, also considered research into the long-term negative health outcomes and recreational participants to be important.

- International Sporting Federations are interested in the conduct of more implementation research and studies that evaluate intervention effectiveness.

How these findings might impact on clinical practice in the future

- Research into concussion management and prevention needs to be extended to sports other than just football codes.

- Future research needs to involve its stakeholders (eg, athletes, sports bodies, etc) from the outset to ensure the incorporation of sport-specific contextual influences that will increase the potential for wide scale adoption and scale-up of prevention research findings.

- Uniting researchers, clinicians and peak sports bodies will ensure more effective practice-policyresearch partnerships that will benefit all athletes.

is known from public health that different parts of the health system (including policymakers, practitioners and researchers) approach issue prioritisation differently and rely on different types of evidence. ${ }^{1-4}$ There is also a recognised disconnect between the available research evidence relating to sports injuries and that which is required to inform 
public health agendas around the protection of sports participants. ${ }^{5}$

International Sporting Federations (ISFs) have an obligation under the Olympic Charter to encourage and support measures to protect athletes. ${ }^{6}$ To do so, their Medical Commissions draw heavily on the available sports medicine research evidence-base. In 2009, the International Olympic Committee (IOC) established its research centre (IOC-RC) programme with the major goal of sharing "scientific research results with the field throughout the Olympic movement and sports community, converting these results into concrete actions to protect the health of all athletes". ${ }^{7}$ However, the alignment of the IOC-RC research priorities with those of ISFs they are meant to assist and inform has not previously been explored.

This is important because of what has been termed the injury-prevention-to safety promotion gap (figure 1), in which researchers use a top down approach to push their findings into prevention, largely ignoring the context in which their findings need to be implemented. ${ }^{8}$ Practitioners, on the other hand, are context-driven and employ a bottom-up approach when using evidence to guide their adoption and use of preventive methods.

The aim of this paper is to provide a first-hand understanding of the injury prevention and illness priority topics and research type needs identified by the ISFs for their sport. These are compared with the IOC-RC research priorities. It is intended that this information will highlight areas for joint future research initiatives to help reduce the evidence-to-prevention gap for the benefit of all those who play sport.

\section{METHODS}

\section{Participants and sampling}

A cross-sectional survey was used to target two groups of participants attending the October 2015 meeting of the ISF Chief Medical Officers (CMOs) and the IOC-RC Directors hosted by the IOC Medical Commission in Lausanne, Switzerland. The first comprised the 32 Medical Chairpersons of the IOC-recognised ISFs who had committed to attending the meeting. The second group comprised the directors of the nine IOC-RCs.

The study was approved by the Federation University Australia Human Research Ethics Committee (Approval: B15-144) and all respondents (including their ISF/IOC$\mathrm{RC}$ ) were guaranteed anonymity in the reporting of results.

\section{Survey design and administration}

An online self-report survey was designed, underpinned by the Translating Research into Injury Prevention Practice (TRIPP) framework. ${ }^{9}$ Two versions of the survey were developed with slightly modified language to best align with respondents from ISFs and the IOC-RCs. The survey began with two questions to determine which ISF/IOC-RC the respondent represented, and their specific role within the organisation. Two open-ended questions then determined their injury prevention and health protection priorities; one focused on injury/ illness prevention priorities and the second identified populations for specific targeting. Five 4-point Likert scale (Very Important, Important, Somewhat Important, Not Important) questions were used to determine the importance of research according to TRIPP stage: (1) injury/illness surveillance (TRIPP stage 1), (2) determining

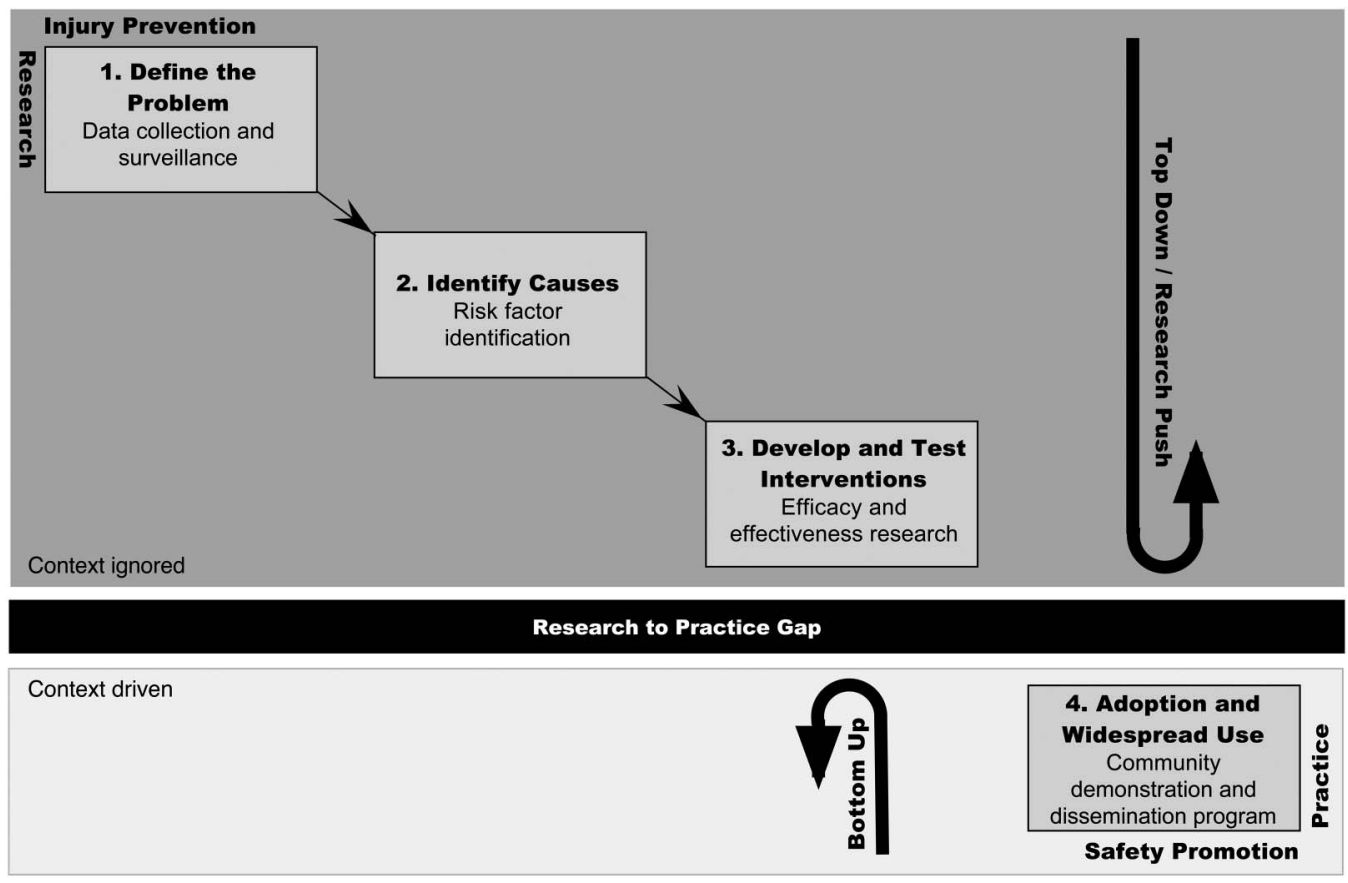

Figure 1 The injury-prevention-to-safety promotion gap. (Reproduced, with permission, from ref. 8). The IOC-RCs can be considered as operating in the research part of this spectrum, and the ISFs in the practice section. IOC-RC, International Olympic Committee Research Centre; ISF, International Sporting Federation. 
the mechanism of injury/illness (TRIPP stage 2), (3) developing strategies to prevent injuries/illness (TRIPP stages 3 and 4, this is combined because it was considered that few of the ISFs would be able to distinguish between developing an injury prevention measure and assessing its efficacy in an ideal condition trial), (4) determining how to best implement injury/illness prevention strategies (TRIPP stage 5) and (5) determining the effectiveness of these strategies (TRIPP stage 6).

The online questionnaire was administered through Lime Survey (http://www.limesurvey.org). Invitations to participate in the survey, followed by several reminders, with direct links to the Plain Language Statement and the survey, were emailed to the ISFs/IOC-RCs by the IOC Medical and Scientific Department 3 weeks before the ISF/IOC-RC meeting. Informed consent was implied by the completion of the online survey.

\section{Response coding and analysis}

Survey responses were directly exported from Lime Survey into Microsoft Excel and responses from the ISFs and IOC-RCs were analysed separately. Thematic analysis was used to examine themes within responses to the two open-ended questions. Two members of the research team (ST and $\mathrm{AB}$ ) jointly developed a coding scheme to establish response central themes and subthemes (as shown in figures 2-5). These authors independently coded all responses into these central themes and ensured consensus coding through discussion.
Responses for injury prevention and athlete health protection priorities were coded into four general themes: injuries, illnesses, injury severity and mechanisms. Responses relating to specific athlete populations were coded into four general themes: gender, age groups, sports and specific athlete groups. When a given survey responder provided no specific response in relation to a central theme, no assumptions were made as to the respondent's preferences.

The frequency ( $\mathrm{n}$ and \%) of responses that aligned with each central and subtheme were determined separately for ISFs and IOC-RCs. The proportion of respondents reporting the importance of each type of prevention research underpinned by TRIPP was calculated and compared graphically.

\section{RESULTS}

Response

Just over two-thirds of the ISFs $(68.8 \%, \mathrm{n}=22)$ responded to the survey. Respondents reported to be a: member/ chairperson of a medical committee $(50 \%, \mathrm{n}=11)$, CMO $(36.5 \%, \mathrm{n}=8)$, medical advisor $(9.0 \%, \mathrm{n}=2)$ or a director of operations $(\mathrm{n}=1)$. Of the nine IOC-RCs, $77.8 \%(\mathrm{n}=7)$ centre directors completed the survey.

\section{ISF injury/illness priorities}

Fewer than $30 \%$ of the ISFs reported injury/illness priorities across all central themes, with the majority relating

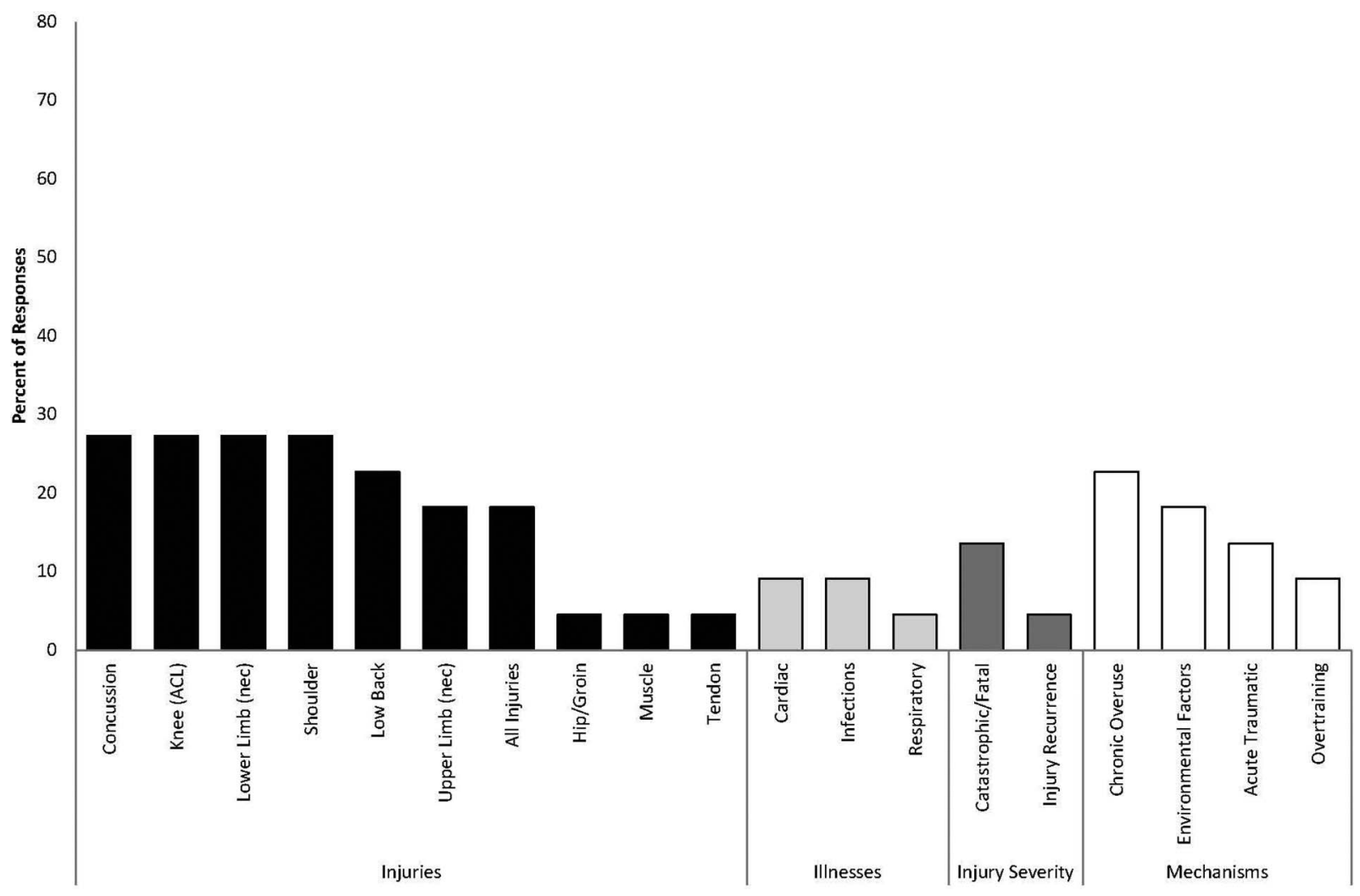

Figure 2 Per cent of International Sporting Federation (ISF) responses that aligned with identified central and subthemes for priorities for injury/illness prevention $(n=22)$. $A C L$, anterior cruciate ligament. 


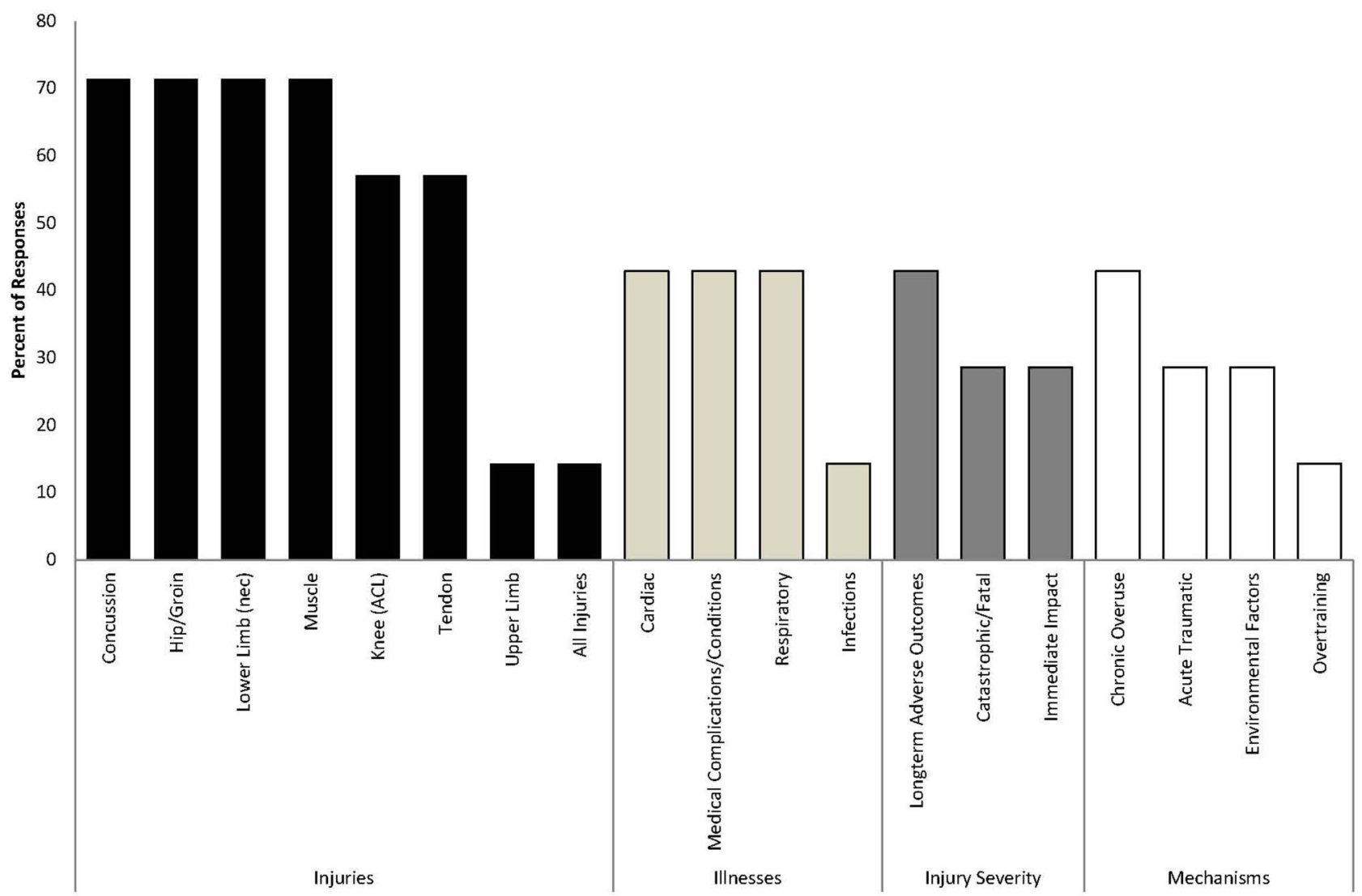

Figure 3 Per cent of International Olympic Committee Research Centre (IOC-RC) responses that aligned with identified central and subthemes for priorities for injury/illness prevention research $(n=7)$. ACL, anterior cruciate ligament.

to injuries (figure 2). The prevention of concussion, anterior cruciate ligament (ACL), lower limb (other than ACL) and shoulder injuries were each prioritised within the 'injury' theme by $27.3 \% \quad(\mathrm{n}=6)$. The prevention of cardiac and infection (eg, skin lesions) illnesses were each reported within the 'illness' priority theme by $9.1 \%(\mathrm{n}=2)$. Within the 'injury severity' theme, catastrophic/fatal injuries were a priority for $13.6 \% \quad(n=3)$. Injuries resulting from chronic overuse and environmental factors were the most common within the 'mechanism priorities' theme, being reported by $22.7 \% \quad(n=5)$ and $18.2 \%(\mathrm{n}=4)$, respectively.

\section{IOC-RC injury/illness priorities}

The IOC-RCs reported injury/illness priorities across all central themes, with particularly strong responses for injuries (figure 3). Within the general theme of 'injury', the most frequent subthemes were concussion, hip/ groin, lower limb injures (other than ACL and hamstring injuries which were grouped separately) and muscle (eg, strains) each being identified by $71.4 \%$ $(n=5)$. Within the general theme of 'illness', cardiac, medical complications/conditions (eg, renal function during physical activity) and respiratory illness were each reported as research priorities by $42.9 \% \quad(n=3)$. In the 'injury severity theme', long-term adverse outcomes of injuries (eg, osteoarthritis) were the most common stated by $42.9 \% \quad(n=3)$. Within the 'injury mechanism' theme, $42.9 \% \quad(n=3)$ aligned their priorities to the chronic overuse subtheme.

\section{ISF athlete target groups}

As displayed in figure 4, ISF responses were coded into five general themes: gender, age groups, sports, specific athlete groups and 'no specific'. A substantial proportion $(36.4 \% ; \mathrm{n}=8)$ indicated that they had no specific target athlete population. While no ISF specifically indicated whether individual sport or team sport athletes were a priority, this was able to be inferred from the nature of the sport they represented, with $72.7 \%(\mathrm{n}=16)$ representing individual sports. From the responses, $18.2 \%(n=4)$ had no specific single gender priorities, but $13.6 \% \quad(n=3)$ indicated that female athletes were a particular focus. Within the age group theme, youth participants were a priority for $40.9 \% \quad(n=9)$. Additionally, elite and Paralympic athlete groups were reported as priorities by $18.2 \%(n=4)$ and $13.6 \%(n=3)$ of ISFs, respectively.

\section{IOC-RC athlete target groups}

There was considerably more variation in the athlete target groups identified by the IOC-RCs (figure 5). Research focused on both genders was important for $42.9 \% \quad(n=3)$, 


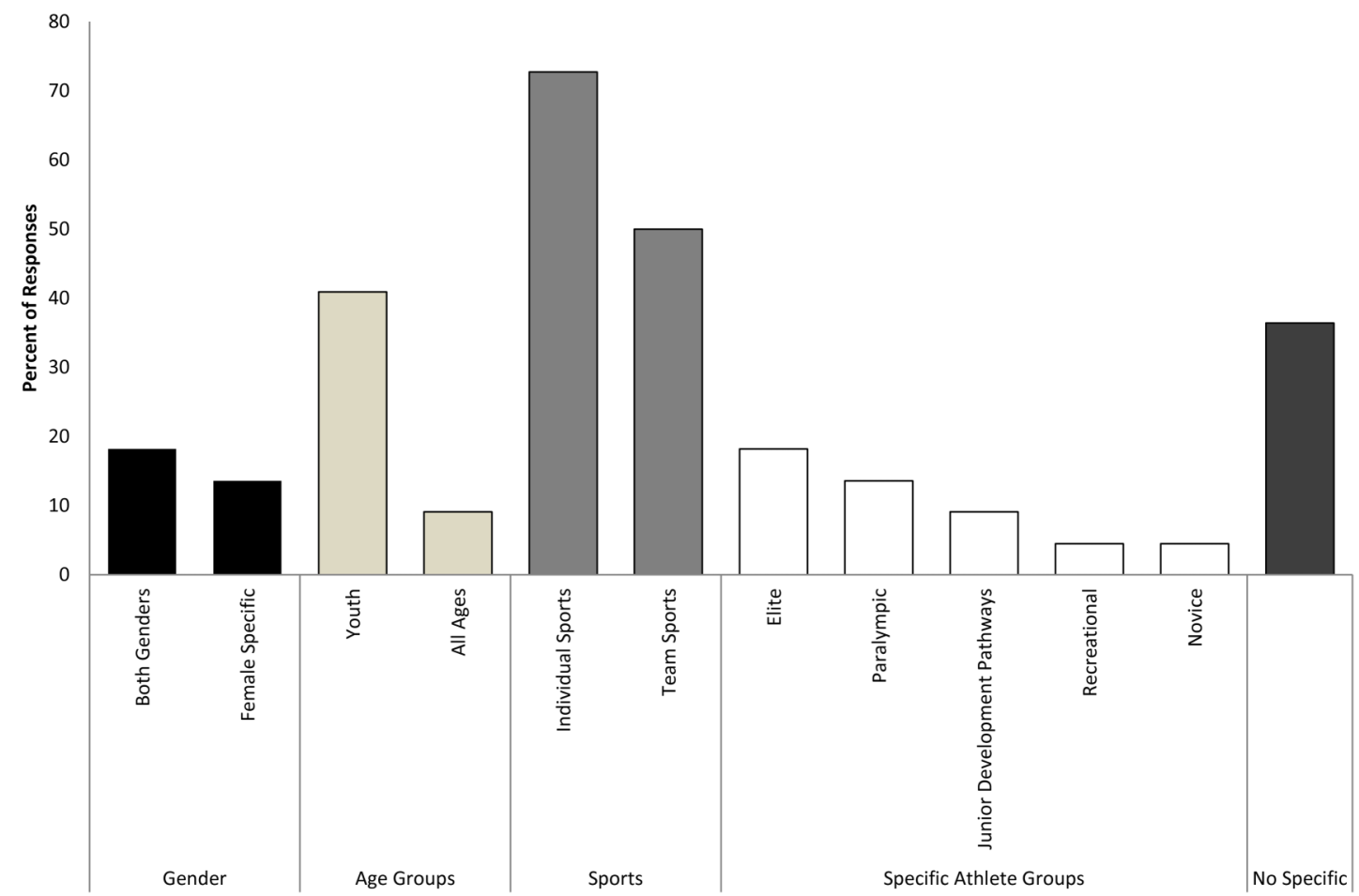

Figure 4 Per cent of International Sporting Federation (ISF) responses that aligned with identified central and subpriority athlete target populations for their injury/illness prevention and health protection practices $(n=22)$.

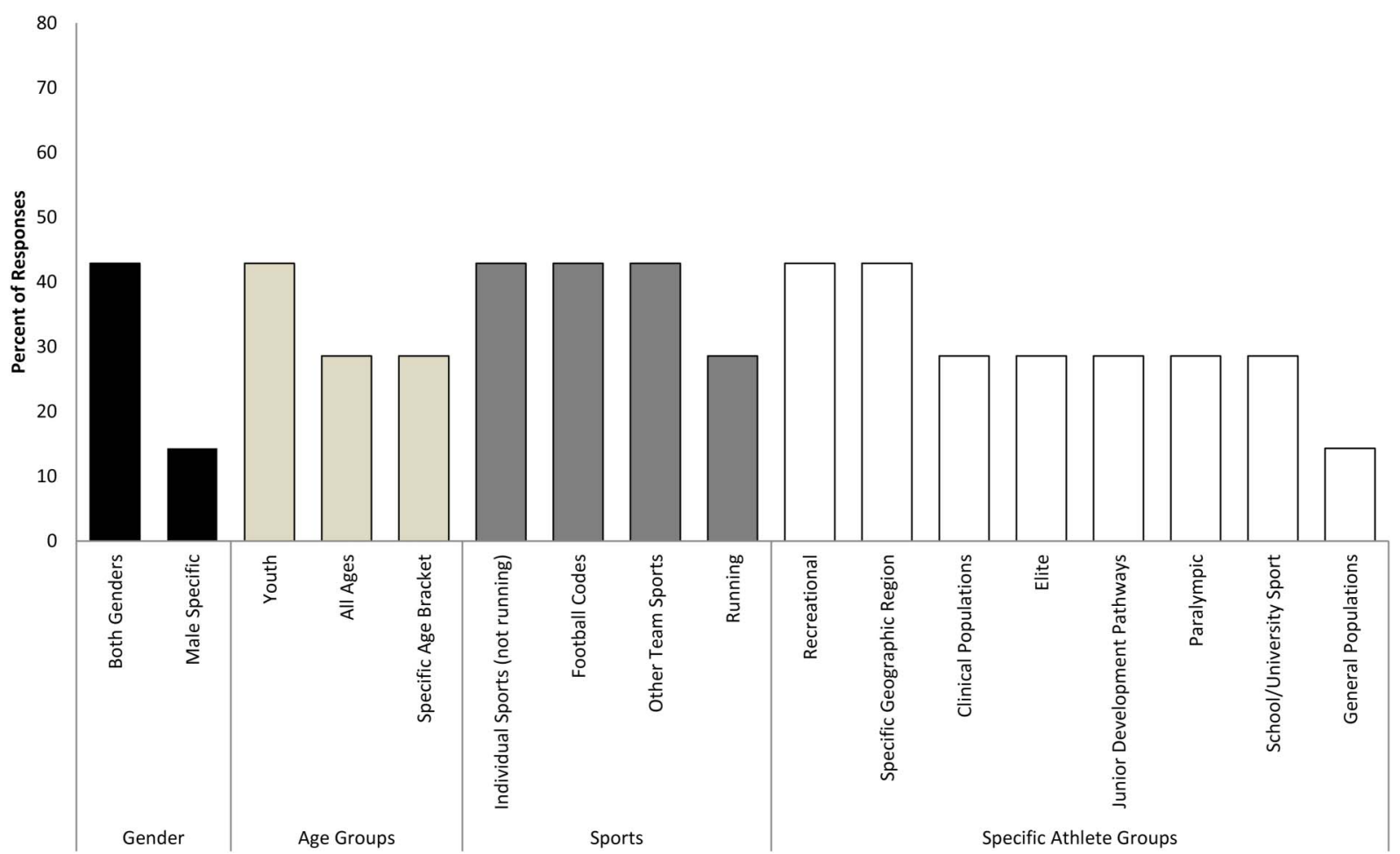

Figure 5 Per cent of International Olympic Committee (IOC-RC) responses that aligned with identified central and subpriority athlete target populations for their injury/illness prevention and health protection practices $(n=7)$.

but several also specifically mentioned male athletes. Youth sporting participants were the most frequently reported age group focus $(42.9 \% ; n=3)$. Individual sports other than running (eg, snow sports), football codes (eg, soccer) and other team sports (eg, basketball, handball) were equally rated by $42.9 \%(n=3)$. Additionally, recreational athletes and athletes from a specific geographic region were the focus of research for $42.9 \%(n=3)$. 


\section{Relative importance of different research types}

There were some differences in the level of importance assigned to some research categories by ISFs and IOC-RCs (figure 6). Injury surveillance research (TRIPP stage 1) was reported to be 'very important' by $71.4 \%$ $(n=5)$ of IOC-RCs but only by $59.1 \% \quad(n=13)$ of ISFs. Research into the mechanism of injury/illness (TRIPP stage 2) was considered 'very important' by $85.7 \%(\mathrm{n}=6)$ of IOC-RCs but only by $59.1 \%(n=13)$ of ISFs. There was more agreement on the need for research to develop preventive strategies (TRIPP stages 3 and 4), with this being rated as 'very important' for $71.4 \% \quad(\mathrm{n}=5)$ of IOC-RCs and $72.7 \%(\mathrm{n}=17)$ of ISFs. Regarding research towards the implementation end of the TRIPP spectrum, there was more variability in responses, ranging from somewhat important to very important. Developing an implementation plan to accompany prevention strategies (TRIPP stage 5) was reported to be 'very important/ important' by only $57.1 \% \quad(n=4)$ of IOC-RCs, compared to $100 \%$ of the ISFs. Similarly, research into determining the effectiveness of preventive strategies (TRIPP stage 6) was rated as 'very important/important' by only $57.1 \%$ $(n=4)$ of IOC-RCs but by $90.0 \%(n=20)$ of the ISFs.

\section{DISCUSSION}

In 2008, Timpka et $a l^{10}$ stated "the management of the sports injury problem will require a constant intermingling between scientific findings, contextual factors and values in both the scientific and policy processes". To achieve this, ongoing improved prevention of injuries and protection of health in athletes will require bridging the gaps between research and practice. This will only be achieved through a mutual understanding and sharing of evidence from all perspectives so as to ensure new common understanding of the problems to be addressed and how to ensure this in the real-world context of sport delivery. ${ }^{311}$ Research conduct is governed by several factors including personal interests, availability of research funding, direct links with sports bodies and the infrastructure available to support it. While there is a major overlap with the needs of the sporting community, very often it is these other factors that drive research activity. On the other hand, in practice settings such as ISFs, there is a strong connection to the needs and priorities of athletes and there are often readily-available and economically-feasible intervention options.

This study is a first attempt at describing the injury prevention and illness priorities and research type needs of ISFs and IOC-RCs. The study is unique in that it is the first time that the views of both groups have been compared. For this reason, a mix of open-ended and Likert scale option questions were used.

\section{Priorities for prevention}

In terms of condition priorities, both IOC-RCs and ISFs agreed that the prevention of concussion was a key priority, reflecting increasing international focus on the

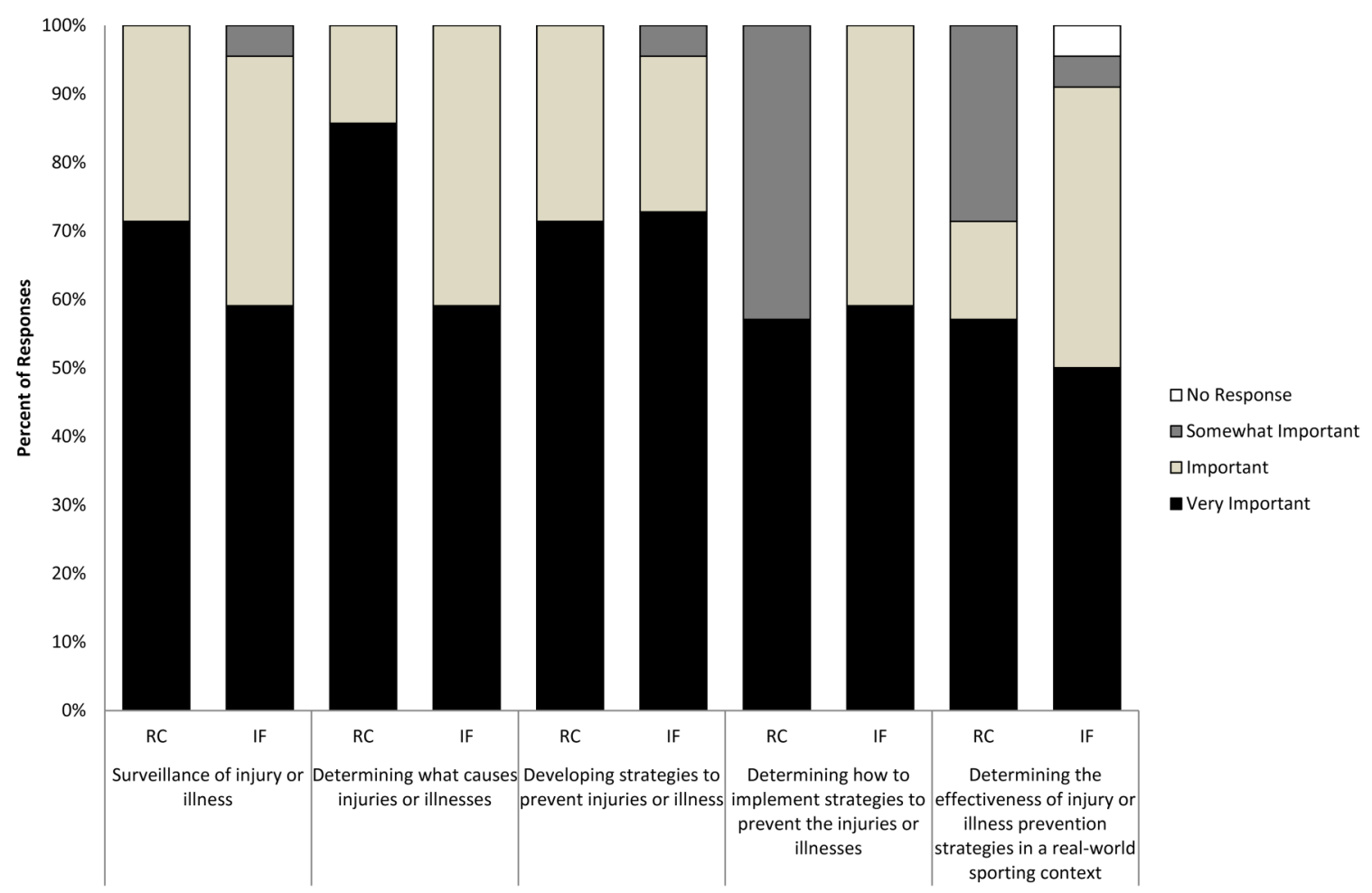

Figure 6 Per cent of International Olympic Committee (IOC-RC) ( $n=7)$, and International Sporting Federation ( $n=22)$ responses indicating the level of importance for different types of injury/illness prevention research outlined in the Translating Research into Injury Prevention Practice (TRIPP) Framework. 
importance of this condition. ${ }^{12}$ This finding provides impetus for IOC-RCs to direct some of their concussion research towards understanding this problem in sports more generally, not just in football codes.

Respiratory illness has been the most commonly reported illness during major elite competitions. ${ }^{13}$ On a proportionate basis, preventing respiratory illness was more of a priority for IOC-RCs than the ISF. It is possible that the responding ISFs had unique illness profiles and that respiratory illness is/has not yet been identified as a significant concern by them.

There is growing evidence that injuries sustained during an athlete's competitive career can result in negative long-term health consequences. ${ }^{14-16}$ However, no ISF specifically indicated that preventing such longterm health impacts were a priority. This appears somewhat contradictory to their prioritisation of concussion and ACL injuries which have been linked to long-term negative health outcomes. ${ }^{15}{ }^{16}$ It is possible that this finding reflects the limited resources available to ISFs, leading to a focus on currently active athletes only.

Both IOC-RCs and ISFs recognised the need to prevent injuries resulting from overuse associated with repetitive loading of the musculoskeletal system without sufficient recovery to allow structural adaptations to occur. ${ }^{17} 18$ There would be benefit in a bringing together of the contextual expertise of the ISFs in quantifying and managing the training and competition demands imposed on athletes, with the specific data analysis/recording skills of the IOC-RFs to significantly reduce the occurrence of injuries/illnesses that are related to both inappropriate prescription of training, especially in the lead-up to major competitive events, and to competition calendars that are highly congested to meet commercial demands.

\section{Population priorities}

Youth athletes were a priority for both IOC-RCs and ISFs. This is a promising finding, because as the professionalisation of youth sport has increased, so have the injury rates within this athlete subpopulation. ${ }^{19}{ }^{20} \mathrm{~A}$ recent IOC statement has called for greater understanding in this setting with its joint yet different priorities of facilitating safe enjoyable participation and fostering talent development. ${ }^{21}$ This suggests a clear opportunity for ISFs and IOC-RFs to come together to have a major impact on the prevention of chronic overuse injuries in youth sport participants.

A substantially larger proportion of IOC-RCs than ISFs indicated that they targeted recreational athletes. This probably reflects the main role of the ISF respondents being to oversee sports medicine provision for elite athletes in international competition. It is a stated aim of the IOC-RCs programme to provide knowledge that leads to prevention of injuries and enhanced health protection in elite and recreational sport participants. $^{7}$

\section{Important research}

There was broad agreement from both IOC-RCs and ISFs that all stages of the TRIPP framework were important to some degree. A lower proportion of ISFs considered surveillance (TRIPP stage 1) to be of high importance than did IOC-RCs. Discussion during the IOC meeting suggested that many ISFs understood what their main issues were and were keen to implement preventive solutions. Others may not have understood the value of surveillance, or how to undertake it in their sport. Similarly, the IOC-RFs were more likely to prioritise fundamental and basic research into the understanding the mechanisms of injury which is not surprising given that many of them are clinical sports medicine groups in strong academic institutions.

The ISFs stated strong support for the need to conduct research into how to implement preventive measures (100\% of ISFs) and demonstrating that they were effective (90\%). This is not surprising given that the ISFs are largely comprised of practitioners who need to implement preventive policy and practice in their roles. Research into these aspects is usually of a more public-health, or healthpromotion, focus and not all of the IOC-RCs have this expertise. Nonetheless, it is becoming evident that better understanding of 'how' to implement prevention strategies into specific sporting contexts would help to bridge the gap between research and practice. ${ }^{11}{ }^{22-24}$ The fact that this type of research is a priority for all ISFs, suggests that future research could capitalise on the existing skills of the IOC-RCs already working in this area.

\section{Limitations}

Overall, there was a very good response rate for this sort of survey, but several reminders were needed to be sent to maximise this and the response rate was less than that achieved in a survey of ISF health priorities. ${ }^{6}$ Not all ISFs/ IOC-RCs responded, including many representing team ball sports, and this may have biased the distribution of responses. For example, no responding ISF was associated with any form of football and the IOC-RCs are not equally distributed across the globe. The results are therefore specific to the responding ISFs/IOC-RCs and the results might have been different if all ISFs/IOC-RCs responded. Moreover, the responses may have been biased by the particular perspective (influenced by their background, experience and role) of the one person from each organisation who completed the survey. Not all ISFs were represented by their CMO at the IOC meeting; neither did all have a functioning medical commission nor a CMO.

\section{CONCLUSIONS}

There is a need for specific investment to bring ISFs and IOC-RCs together to jointly drive future research agendas. Understanding the priorities of the ISFs as end-users of the research conducted by the IOC-RCs is important to ensure meaningful impact from research that has been designed and conducted to mimic the real- 
world context of sport delivery from the outset. Current ISF/IOC-RC prevention priorities align well for concussion, ACL injuries and chronic overuse injuries with particular emphasis on youth. They do not align regarding the long-term negative health outcomes or recreational participants. The ISFs gave more priority to implementation research and evaluation needs, while the IOC-RCs prioritised more fundamental and clinical research necessary to underpin the development of preventive measures. Paraphrased using the language of Hanson $e t a l,{ }^{11}$ the IOC-RC priorities were more aligned with understanding 'what should be done', but the ISFs, as policy and practitioner stakeholders, want more research about 'what can be done' and 'how it needs to be done'.

Going forward, it will be important that research aiming to prevent injuries and illnesses in athletes involves stakeholders of this research from the outset. This will enable better designed research studies to make an impact because of their incorporation of contextual influences for the outset and potential for wide scale adoption and scale-up across the broader sports communities. Future IOC Medical Commission activities, better linking the ISFs and the IOC-RCs, will lead to the development of more effective practice-policy-research partnerships that will benefit all athletes. This will need to be informed by more in-depth data (eg, obtained through focus group discussions) about research priorities from a broader range of representatives from the ISFs. Bringing the ISFs/IOC-RCS together to jointly drive future research agendas will be important.

Acknowledgements Jennifer Donzé, of the IOC Medical and Scientific Department, is thanked for her assistance in inviting people to complete the survey and doing follow-up reminders. Dr Alex Donaldson, of ACRISP, provided input into the early stages of this project.

Contributors The study was conceived and designed by CF. The survey development was led and administered by ST. CFF, TS and LE contributed to the survey design. TS and LE provided the link to the IOC Medical Commission. ST and AB undertook the data management and data analysis. All authors contributed to the interpretation of the data and the writing and/or editing of the manuscript.

Funding CF was funded by an NMHRC Principal Research Fellowship (ID: 1058737). ST was funded through a Robert HT Smith Postdoctoral Research Fellowship though Federation University Australia. Aspects of this study were funded through an IOC Research Centres Grant to the Australian Collaboration for Research into Injury in Sport and its Prevention (ACRISP) at Federation University Australia.

Competing interests CF and LE are the Director/Deputy Director of two of the research centres invited to participate in this survey.

Ethics approval This project was approved by the Federation University Australia Human Research Ethics Committee as A15-068.

Provenance and peer review Not commissioned; externally peer reviewed.

Data sharing statement No additional data are available.

Open Access This is an Open Access article distributed in accordance with the Creative Commons Attribution Non Commercial (CC BY-NC 4.0) license, which permits others to distribute, remix, adapt, build upon this work noncommercially, and license their derivative works on different terms, provided the original work is properly cited and the use is non-commercial. See: http:// creativecommons.org/licenses/by-nc/4.0/

\section{REFERENCES}

1. Brownson $\mathrm{RC}$, Jones $\mathrm{E}$. Bridging the gap: translating research into policy and practice. Prev Med 2009;49:313-15.

2. Davis F, Peterson C, Bandiera F, et al. How do we more effectively move epidemiology into policy action? Ann Epidemiol 2012;22:413-16.

3. Glasgow RE, Green LW, Taylor MV, et al. An evidence integration triangle for aligning science with policy and practice. Am J Prev Med 2012;42:646-54.

4. Choi BC, Li L, Lu Y, et al. Bridging the gap between science and policy: an international survey of scientists and policy makers in China and Canada. Implement Sci 2016;11:16.

5. Finch CF. Getting sports injury prevention on to public health agendas-addressing the shortfalls in current information sources. Br J Sports Med 2012;46:70-4.

6. Mountjoy M, Junge A. The role of International Sport Federations in the protection of the athlete's health and promotion of sport for health of the general population. Br J Sports Med 2013;47:1023-7.

7. Engebretsen L, Bahr R, Cook JL, et al. The IOC Centres of Excellence bring prevention to sports medicine. Br J Sports Med 2014;48:1270-5.

8. Hanson DW, Finch CF, Allegrante JP, et al. Closing the gap between injury prevention research and community safety promotion practice: revisiting the public health model. Pub HIth Rep 2012;127:147-55.

9. Finch C. A new framework for research leading to sports injury prevention. J Sci Med Sport 2006;9:3-9.

10. Timpka T, Finch CF, Goulet C, et al. Meeting the global demand of sports safety: the intersection of science and policy in sports safety. Sports Med 2008;38:795-805.

11. Hanson D, Allegrante JP, Sleet DA, et al. Research alone is not sufficient to prevent sports injury. Br J Sports Med 2014;48:682-4

12. McCrory $\mathrm{P}$, Meeuwisse $\mathrm{WH}$, Aubry M, et al. Consensus statement on concussion in sport: the 4th International Conference on Concussion in Sport held in Zurich, November 2012. Br J Sports Med 2013;47:250-8.

13. Engebretsen L, Soligard T, Steffen K, et al. Sports injuries and illnesses during the London Summer Olympic Games 2012. Br J Sports Med 2013;47:407-14.

14. Maffulli N, Longo UG, Gougoulias N, et al. Long-term health outcomes of youth sports injuries. Br J Sports Med 2010;44:21-5.

15. Lohmander LS, Englund PM, Dahl LL, et al. The long-term consequences of anterior cruciate ligament and meniscus injuries: osteoarthritis. Am J Sports Med 2007;35:1756-69.

16. Guskiewicz KM, Marshall SW, Bailes J, et al. Recurrent concussion and risk of depression in retired professional football players. Med Sci Sports Exerc 2007;39:903-9.

17. DiFiori JP, Benjamin HJ, Brenner JS, et al. Overuse injuries and burnout in youth sports: a position statement from the American Medical Society for Sports Medicine. Br J Sports Med 2014:48:287-8.

18. Drew MK, Finch CF. The relationship between training load and injury, illness and soreness: a systematic and literature review. Sports Med 2016;46:861-83.

19. Emery C, Tyreman H. Sport participation, sport injury, risk factors and sport safety practices in Calgary and area junior high schools. Paed Child HIth 2009;14:439-44.

20. Finch CF, Wong Shee A, Clapperton A. Time to add a new priority target for child injury prevention? The case for an excess burden associated with sport and exercise injury: population-based study. BMJ Open 2014;4:e005043.

21. Bergeron MF, Mountjoy M, Armstrong $\mathrm{N}$, et al. International Olympic Committee consensus statement on youth athletic development. $\mathrm{Br}$ J Sports Med 2015;49:843-51.

22. Finch CF. No longer lost in translation: the art and science of sports injury prevention implementation research. $\mathrm{Br} J$ Sports Med 2011;45:1253-7.

23. Finch CF, Donaldson A. A sports setting matrix for understanding the implementation context for community sport. Br J Sports Med 2010;44:973-8.

24. O'Brien J, Finch CF. The implementation of musculoskeletal injury-prevention exercise programmes in team ball sports: a systematic review employing the RE-AIM framework. Sports Med 2014;44:1305-18. 